\title{
BAKHTIN, CIÊNCIAS HUMANAS E PSICOLOGIA: DIÁLOGOS SOBRE EPISTEMOLOGIA E PESQUISA
}

\section{BAJTÍN, CIENCIAS HUMANAS Y PSICOLOGÍA: DIÁLOGOS SOBRE EPISTEMOLOGÍA $\Upsilon$ INVESTIGACIÓN \\ BAKHTIN, HUMAN SCIENCES AND PSTCHOLOGY: DIALOGUES ABOUT EPISTEMOLOG $\mathcal{Y}$ AND RESEARCH}

\author{
Jardel Pelissari Machadoํㅜ e Andrea Vieira Zanella² \\ ${ }^{1}$ Universidade Federal do Paraná, Curitiba/PR, Brasil \\ ${ }^{2}$ Universidade Federal de Santa Catarina, Florianópolis/SC, Brasil
}

\begin{abstract}
RESUMO: Este ensaio teórico, com foco em questões epistemológicas e ontológicas, compõe uma teia de diálogos entre as vozes dos pensadores do Círculo de Bakhtin e as vozes da Modernidade para apresentar, a partir da Filosofia do Ćrculo, elementos que auxiliem a pensar uma forma outra de pesquisa em Ciências Humanas e, mais especificamente, em Psicologia. Com base nessa incursão discute-se três principais aspectos e seus efeitos à produção de saberes: o lugar do/a pesquisador/a e seu/sua outro/a; o trabalho de escrita de pesquisa e o ideal de verdade do saber.

PALAVRAS-CHAVE: Círculo de Bakhtin; Epistemologia; Ciência Moderna; Pesquisa em Ciências Humanas; Psicologia.
\end{abstract}

RESUMEN: Este ensayo, con foco en cuestiones epistemológicas y ontológicas, al componer una red de diálogos entre las voces de los pensadores del Círculo de Bakhtin con las voces de la Modernidad, objetiva presentar, a partir de la Filosofía del Círculo, elementos que ayuden a pensar y hacer una forma otra de investigación en Ciencias Humanas y en Psicología. Con base en esta incursión se discuten tres principales aspectos y sus efectos a la producción de saberes en la Psicología: el lugar del investigador / a y su otro / a; el trabajo de escritura de investigación; y el ideal de verdad del saber.

PALABRAS-CLAVE: Círculo de Bajtín; Epistemología; Ciencia Moderna; Investigación en las Ciencias Humanas; Psicología.

ABSTRACT: This essay, focusing on epistemological and ontological questions, in composing a web of dialogues between the voices of the Bakhtin's Circle and the voices of Modernity, aims to present, from the Philosophy the Circle, elements that support to think another form of research in Humanities and Psychology. Based on this incursion, three main aspects and their effects on the production of knowledge are discussed: the place of the researcher and their other; the writing work research; and the true ideal of knowledge.

KEYWORDS: The Bakhtin Circle; Epistemology; Modern Science; Research in Humanities; Psychology. 


\section{Introdução}

A história e a filosofia da ciência são terrenos nos quais se evidenciam tensões várias. Discussões sobre o modo como se constitui o conhecimento e seu estatuto de verdade, bem como sobre o lugar do/a pesquisador/a no processo de produção de conhecimentos, são recorrentes e visibilizam essas tensões. Tratam-se de discussões que produzem efeitos não apenas no universo acadêmico/científico, mas numa esfera social mais ampla, pois os conhecimentos produzidos impactam nos modos de organização de uma dada sociedade, incidindo sobre os modos de ser e agir das pessoas que a compõem. Nessas tensões entre as diferentes formas de compreender a produção de conhecimentos, algumas vozes ocupam lugares centrais nas relações de poder, subjugando as demais.

Inserido nesse diálogo tenso e polêmico, o Círculo de Bakhtin ${ }^{1}$ apresenta-se como uma voz insurgente, contrapondo-se à tradição científica que se constituiu hegemônica a partir da Modernidade. Assim, neste ensaio, buscamos construir diálogos entre as vozes do Círculo de Bakhtin e as vozes da Modernidade. Ao fazê-lo, temos por objetivo extrair elementos que nos auxiliem a pensar uma forma outra de pesquisa nas ciências humanas e, em especial, na Psicologia.

Para compor esses diálogos, selecionamos algumas obras que compõem o conjunto de textos do Círculo em que é mais evidente a contraposição às vozes da Modernidade. São escritos que nos auxiliam a compreender o posicionamento epistemológico e ontológico do grupo e sobre os quais temos nos dedicado a estudar, a saber: (a) de Mikhail Bakhtin: Os gêneros do discurso; Para uma filosofia do ato responsável; O autor e a personagem na atividade estética; Por uma metodologia das ciências humanas; e Fragmentos dos anos 19701971; (b) de Valentin Volóchinov: Marxismo e filosofia da linguagem; O freudismo² Palavra na vida e palavra na poesia; e A construção da enunciação.

Apresentamos, de início, uma citação de Bakhtin constantemente apresentada em trabalhos acadêmicos sobre a produção de conhecimentos em ciências humanas:

As ciências exatas são uma forma monológica do saber: o intelecto contempla uma coisa e emite um enunciado sobre ela. Aí só há um sujeito: o cognoscente (contemplador) e falante (enunciador). A ele só se contrapõe a coisa muda. Qualquer objeto do saber (incluindo o homem) pode ser percebido e conhecido como coisa. Mas o sujeito como tal não pode ser percebido e estudado como coisa porque, como sujeito e permanecendo sujeito, não pode se tornar mudo; consequentemente, o conhecimento que se tem dele só pode ser dialógico. (Bakhtin, 2017b, p. 66 - grifos do autor)

Dialogando com essa citação, perguntamos: o que Bakhtin quis dizer ao afirmar que as ciências exatas são monológicas, ou que o conhecimento do sujeito só pode ser dialógico? De que forma essas afirmações podem nos auxiliar a pensar o pesquisar em Psicologia de modo que nosso outro não seja transformado em "coisa muda"?

A partir desse excerto, passaremos a tecer algumas teias dialógicas que nos auxiliarão a compreender não apenas a que voz(es) Bakhtin e o Círculo respondem, mas também a refletir sobre o modo como temos e podemos vir a produzir conhecimentos em Psicologia. Iniciamos, pois, nossa incursão dialógica pela Modernidade, com seus pensadores 
e ideais para, na sequência, apresentar o posicionamento do Círculo frente às seguintes temáticas: o lugar do/a pesquisador/a e de seu/sua outro/a; o trabalho de escrita na pesquisa; o ideal de verdade do conhecimento.

\section{Modernidade e o indivíduo}

A Modernidade constituiu-se como um período da história no qual é possível identificar, a partir do século XVII, uma série de transformações na organização social e nas formas de viver nas sociedades europeias, as quais se tornaram mundialmente influentes (em maior ou menor grau), constituindo muito da forma de organização de nossas vidas na atualidade. Na Modernidade consolidou-se uma série de formas de pensamento que produziram o que conhecemos hoje por ciência, em oposição a dogmas e crenças que regiam, anteriormente, a vida nas sociedades europeias.

Ao produzir transformações sociais, a Modernidade também instituiu novos processos de formação de subjetividades, de possibilidades de pensabilidades e sensibilidades. Esse processo, porém, precisa ser analisado e pensado tomando-se esse período histórico como aliado, efeito e causa do avanço e consolidação do modelo econômico capitalista. Nesse contexto econômico, político (com a ascensão da burguesia, destituição de monarquias e de sociedades feudais) e científico, as sociedades modernas, assim como os centros urbanos, foram sendo construídos pautados com base em ideais racionalistas, aliadas a, e de forma a, privilegiar aquilo que era importante ao capitalismo: a produção e circulação de bens de consumo e de pessoas (Lefebvre, 1991, 2013; Santos, 2014).

Modernidade e capitalismo produzem, assim, a apropriação individual do corpo, que é transformado em mercadoria/força de trabalho; promovem a aceleração da vida, na mesma esteira de aceleração e circulação de bens e pessoas, assim como seu fechamento gradativo em espaços e ambientes particulares/privados, com declínio dos espaços públicos e das noções de coletividade; em decorrência, afirmam a centralidade de interesses particulares e de suas próprias necessidades, criadas pelo capital (Benjamin, 2015; Elias, 1998; Santos, 2014). No mesmo processo, a sustentar essa lógica, os ideais liberais constituem a compreensão de sujeito livre, a determinar sua vida, a decidir o lugar a ocupar na sociedade - a participação social fica, por conseguinte, atrelada à produção e ao consumo de mercadorias (Lefebvre, 1991).

Decorrente desse processo, segundo análise de Figueiredo (2000), as relações sociais passam a ser marcadas por um caráter instrumental e pela luta de interesses particulares. O individualismo passa, gradativamente, a produzir uma espécie de ruptura com o outro, afastamento que desconsidera sua importância no próprio processo de afirmação de um possível eu. Há, pois, não mais a constituição de grupos e coletivos, mas de multidões (principalmente nos grandes centros urbanos), espécies de massas amorfas, constituídas por indivíduos e suas individualidades, que passam a conduzir suas vidas com base em interesses particulares (Benjamin, 2015). Como herança dessa forma de pensamento, o outro passa a ser considerado apenas no que se refere as estratégias de obediência e controle prévio, enquanto objeto a ser controlado - a manutenção da pressuposta liberdade que não afeta a liberdade dos demais. 


\section{Ciência moderna e seus preceitos}

O processo histórico que produziu o que se tem qualificado como Ciência está atrelado ao avanço e centralidade do modelo econômico capitalista tal como referido, sendo uma efeito e causa da outra. Para a produção de conhecimentos reais e verdadeiros institui-se, na Modernidade, a rigorosidade do método (forma de se produzir conhecimentos testada e reiterada) como condição e possibilidade para que isso se efetive. O método da ciência moderna apresenta como elementos principais: o caráter anticientífico do sujeito, com condições para que seja neutralizado; a centralidade de aspectos quantificáveis e controláveis, bem como de categorias explicativas universalizantes.

O caráter anticientífico do sujeito compõe e acompanha a formação da noção de indivíduo e, consequentemente, do individualismo. A regular vigilância sobre si (sujeito que produz o conhecimento) emerge no mesmo contex to de transformações da Idade Moderna, com os ideais de cientificidade sustentados por Francis Bacon (1561-1626), Galileu Galilei (1564-1642), René Descartes (1596-1650) e outros que os seguiram, como John Locke, David Hume etc. Com a "virada científica", a filosofia empirista de Bacon, principalmente, produz como efeitos as concepções de "homem" (sujeito genérico) como o senhor, por direito, da natureza, e de conhecimento como o meio para conquistar esse lugar. Assim, o conhecimento passa a ser pensado a partir de um caráter utilitário.

A ciência passa então a modelar suas práticas pela definição de procedimentos e técnicas com base em cálculos e em testagens. Em busca de um conhecimento verdadeiro, funda-se a desconfiança sistemática em relação a possíveis equívocos produzidos pelo próprio homem. Essa desconfiança referia-se: por um lado, sustentado pelo racionalismo cartesiano, às experiências imediatas (ademais a necessidade de base empírica para a constituição do conhecimento); ou, por outro lado, com o empirismo de Bacon, ao fato de que "o intelecto não regulado e sem apoio é irregular e de todo inábil para superar a obscuridade das coisas" (Bacon, 2003, p. 10). Se discordam quanto à primazia do racionalismo ou do empirismo, em um aspecto ambos parecem concordar: a necessidade da constituição de um método, um modo de produzir conhecimento, um "auxílio adequado" para que não se caia no erro de admirarmos e exaltarmos de modo falso os poderes da mente humana" (Bacon, 2003, p. 8), ou, para Descartes (1989), a constituição de "regras para a direção do espírito" (p. 22), para que seja possível a constituição de um “conhecimento certo e evidente” (p. 14).

Decorrente dessas desconfianças, criam-se regras metodológicas às quais o/a pesquisador/a deveria se submeter conscienciosamente. Institui-se duas cisões: "conhecimento científico e conhecimento do senso comum, por um lado, e entre natureza e pessoa humana, por outro" ( Santos, 2008, p. 24); e a separação entre o que é objetivo (passível de verificação) e o que é subjetivo (inerente ao sujeito, essência, falibilidade). Assim, ao humano passam a ser atribuídas características como arbítrio e instabilidade. Compõe-se um quadro no qual a doutrina dos ídolos, na qual Bacon (2003) sustenta seu ideal de "tendência anticientífica do espírito”, e a dúvida metódica, instaurada por Descartes (1996), apresenta-se como embriões dos discursos de suspeita, com vistas a identificar e extirpar (ou ao menos neutralizar) as incertezas produzidas pela falibilidade humana. Esse espírito humano passa a ser denominado/concebido como subjetividade pelo Positivismo de Auguste Comte (1798-1857), o qual intensifica a cisão subjetividade/objetividade e os fundamentos de autocorreção e vigilância na busca pela verdade. Desse modo, como afirma Figueiredo (2000), a Modernidade define-se "pela co-presença destes ataques ao sujeito 
empírico do conhecimento, pelas táticas de defesa contra sua intrusão indesejada, pelo sítio armado em torno da subjetividade" (p. 18).

Os objetos para a ciência, a partir da Modernidade, passam a ser quantificados, ou seja, pensados e olhados a partir de características mensuráveis. Dentre as várias disciplinas existentes, apenas a Aritmética e a Geometria estariam "isentas de todo defeito da falsidade ou de incerteza”, segundo Descartes (1989, p. 16). Além de dimensões mensuráveis, o método científico proposto por Descartes pautava-se na compreensão de que para se responder a uma questão "devemos abstraí-la de todo o conceito supérfluo, reduzi-la à maior simplicidade e dividi-la em partes tão pequenas quanto possível, enumerando-as" (Descartes, 1989, p. 83). Essa divisão serviria para distinguir as condições iniciais, aquelas que ofuscam uma clara compreensão, das leis da natureza, identificadas posteriormente. Produz-se, assim a premissa de que as partes menores seriam mais simples e que, da mesma forma, estudando-se as partes, seria possível remontar o todo e conhecê-lo em sua complexidade.

Sobre esse mesmo aspecto, Ginzburg (1989) chama a atenção para o que define como “o significado epistemológico (e simbólico) de Galileu Galilei para a ciência em geral” (p. 156). Contemporâneo de Descartes, os estudos de Galilei impactaram a constituição do lugar de poder das ciências matemáticas, assim como a organização racional do tempo no sistema capitalista e nas formas de vida nas sociedades atuais (Elias, 1998). As ciências matemáticas se sustentavam numa natureza diversa das disciplinas que se atinham a aspectos qualitativos - importava, pois, o quantificável. Ao abordar o processo histórico de constituição desse lugar central das ciências matemáticas, Ginzburg (1989) conclui que a ciência galileana "poderia adotar o lema escolástico individuum est ineffabile, do que é individual não se pode falar” (Ginzburg, 1989, p. 156). A centralidade na forma de produção de conhecimento decorrente daí está em aspectos quantificáveis e na repetibilidade dos fenômenos.

Na esteira dessa compreensão, a ciência que se desenha a partir de paradigmas mecanicistas, empiristas, racionalistas, e mais tarde com o positivismo e o estruturalismo, busca traçar leis gerais, reconhecer o que permanece e se reproduz - o rigor científico é, pois, dado pelo rigor das medições. Institui-se a compreensão de que só é possível a produção de conhecimentos por duas formas: "as disciplinas formais da lógica e da matemática e as ciências empíricas segundo o modelo mecanicista das ciências naturais” (Santos, 2008, p. $33)$.

Para Ginzburg (1989), há na história das ciências duas grandes vias que estiveram sempre em constante atrito e que aparecem como possibilidades de construção de conhecimento. Uma delas, sustentada e perpetuada pelas disciplinas da lógica e das ciências naturais, sacrifica o conhecimento do que possa ser identificado como individual, ou que escape às regras, regularidades e generalizações. Orientadora das ciências naturais desde o século XVI, passa, a partir do século XIX, com o Positivismo e também com o Estruturalismo, a ser seguida também pelas ciências sociais (e/ou humanas), que buscavam aplicar as mesmas regras metodológicas e bases epistemológicas ao estudo das sociedades. Dentre os marcos dessa passagem consta os estudos de Ferdinand de Saussure (1857-1913) que, com base na perspectiva estruturalista, buscou estudar a língua, a única que é "suscetível duma definição autônoma e fornece um ponto de apoio satisfatório para o espírito" (Saussure, 2006, p. 17), distinguindo-a da linguagem, que é "multiforme e heteróclita […] não se deixa classificar em nenhuma categoria de fatos humanos, pois não se sabe como inferir 
sua unidade" (Saussure, 2006, p. 17). A língua é, portanto, dotada de regularidades, o que constitui a possibilidade de estudá-la como sistema com características quantificáveis e mensuráveis. As ciências sociais e humanas, tais quais o proposto no Estruturalismo, por Saussure e Claude Lévy-Strauss, (1908-2009) ou no Positivismo, por Émile Durkheim (1858-1917), passaram a buscar ferramentas metodológicas e epistemológicas das ciências naturais para o estudo da sociedade, do homem e suas faculdades.

A outra via apontada por Ginzburg (1989) é a via marginalizada. Ao contrário da anterior, busca elaborar um conhecimento que também privilegia o individual. Essa, segundo Santos (2008), reivindica um "estatuto epistemológico e metodológico próprio, com base na especificidade do ser humano e sua distinção polar em relação à natureza” (p. 33). Essa segunda via "será sempre uma ciência subjetiva e não objetiva" (Santos, 2008, p. 38), e sua busca pela compreensão de fenômenos deve se dar a partir de métodos de investigação e critérios epistemológicos distintos dos das ciências naturais. Para tal, o caminho passa por métodos qualitativos com vistas à produção de conhecimento intersubjetivo, descritivo e compreensivo, e não objetivo e explicativo.

\section{Círculo de Bakhtin: conhecimento teórico e vida concreta}

Com base na distinção apresentada por Ginzburg (1989), pode-se identificar a filosofia do Círculo como pertencente à segunda via, marginalizada. Em Para uma filosofia do ato responsável (PFAR), Bakhtin (2010) apresenta uma importante distinção entre a verdade istina - valor abstrato, como ideal universal -; e a verdade pravda - singular, da entonação do ato. Essa distinção será enfatizada por Bakhtin como uma forma de refutar os argumentos da ética kantiana, conforme analisa Sobral (2005). Ao mesmo tempo, apresenta-se como resposta também aos pensadores da Modernidade. Ao abordar o evento único do ser para refutar a ética transcendental kantiana, Bakhtin sinaliza também para a limitação do conhecimento, que denomina teoricismo: um conhecimento que se constitui como abstração das situações concretas da vida, como tentativas de acabamento, fixação de sentidos.

Enquanto abstração, esse conhecimento não pode dar conta de explicar a vida em sua singularidade, pois, se a verdade do mundo teórico (istina) pudesse orientar, de fato, a vida prática, seríamos conduzidos, segundo Bakhtin (2010), a um confinamento, um existir "cientificamente cognoscível congelado" (p. 53), ou, ainda, um mundo no qual o existir não teria lugar. O mundo da cultura, dentro do qual estaria o teoricismo (conhecimento abstrato), portanto, não pode abarcar o mundo da vida, pois "a singularidade única não pode ser pensada, mas somente vivida de modo participativo" (Bakhtin, 2010, p. 58). No mesmo sentido, o ato, afirma Bakhtin (2010), constitui-se sempre singular, pois "no momento do ato, o mundo se reestrutura em um instante, a sua verdadeira arquitetura se restabelece, na qual tudo o que é teoricamente concebível não é mais que um aspecto" (Bakhtin, 2010, p. 53).

Ainda em sua crítica ao teoricismo, Bakhtin (2010) afirma que ele não poderá abstrair do mundo da vida regras universalmente válidas - a vida é maior que a abstração, ela lhe escapa. Quanto a esse mesmo aspecto, em Marxismo e Filosofia da Linguagem (MFL) (Volóchinov, 2017) há outros trechos do mesmo conjunto crítico à filosofia que busca abarcar o mundo da vida no mundo da cultura. Em MFL, Volóchinov dirige-se a 
várias perspectivas: ao mecanicismo (base das ciências naturais) adotado pelos marxistas para explicar a relação entre infra e superestrutura; ao psicologismo idealista de Wilhelm Dilthey (1833-1911), que "repete a tendência geral de todo o idealismo: retirar do mundo material todo o sentido, toda a significação, para colocá-lo no espírito, que se encontra fora do tempo e do espaço" (Volóchinov, 2017, p. 119 - grifo do autor); ao individualismo subjetivista, que centra a produção linguística em um psiquismo individual - defendido por Alexander von Humboldt (1769-1859), na lingüística, e por Wilhelm Wundt (1832-1920), na Psicologia; e ao objetivismo abstrato, que estuda a língua, conforme descrito acima, como sistema dotado de regularidades, separando-o de seus usos reais (linguagem), sendo Saussure, "a expressão mais clara do objetivismo abstrato" (Volóchinov, 2017, p. 164). Ainda quanto às críticas, em O Freudismo (Bakhtin, 2004), Volóchinov as tece quanto à obra de Sigmund Freud (1856-1939), destacando constantemente o afastamento do conhecimento proposto em relação à vida concreta e a negligência de aspectos singulares, sociais e históricos das análises freudianas.

Nesse mesmo sentido de argumentação, em PFAR, Bakhtin (2010) tece considerações que auxiliam a pensar não apenas o conhecimento, mas também a relação entre o sujeito que pesquisa e a pessoa com a qual pesquisa, assim como a responsabilidade implícita nesse ato.

Compreender um objeto significa compreender meu dever em relação a ele (a orientação que preciso assumir em relação a ele), compreendê-lo em relação a mim na singularidade do existir-evento: o que pressupõe a minha participação responsável, e não a minha abstração. (Bakhtin, 2010, p. 66)

Nesse processo de compreensão, o lugar que se ocupa frente ao outro com o qual se pesquisa não pode ser uma abstração: não há um lugar neutro, isento, pois toda compreensão/interpretação é sempre responsiva (Bakhtin, 2010, 2016). Não sendo abstração, é ato realizado no mundo da vida, inserido nela, em seu fluxo constante. $\mathrm{O}$ ato precisa ser compreendido, portanto, como ato em realização concreta, e não tomado após sua realização. Trata-se de uma ação que, como analisa Sobral (2005, p. 20), é "concreta (ou seja, inserida no mundo vivido) intencional (isto é, não involuntária) praticada por alguém situado, não transcendente". $\mathrm{O}$ ato tem, pois, caráter responsivo e de responsabilidade de seu agente. $\mathrm{O}$ ato inscreve, segundo (Bakhtin, 2010, p. 80 - grifo do autor) o "desabrochar da mera possibilidade na singularidade da escolha uma vez por todas”. No ato, há a superação da hipótese, da possibilidade, pois constitui-se como irremediável, irrevogável, uma decisão final e consumada - possibilidade transformada em ato responsável real, um "não-álibi no existir" (Bakhtin, 2010, p. 99 - grifo do autor).

O foco de Bakhtin (2010) será, portanto, o singular, o irrepetível, a impossibilidade de recuperação, restituição de sentido ou representação do ato singular, a impossibilidade da reprodução, e não a busca de leis universais. Para Ponzio (2010), o texto de Bakhtin (2010) indica "uma clara tomada de posição contra qualquer forma de absolutização" (p. 17) , pois compreende que "nenhum princípio ou valor subsiste como idêntico e autônomo, como constante, separado do ato vivo do seu reconhecimento como princípio válido ou valor" (Ponzio, 2010, p. 17). No fluxo incessante da vida, o conhecimento abstrato não é mais do que um aspecto do ato, não sua totalidade - importa, pois, a singularidade do ato, a abertura do mundo da vida e o existir-evento único. 


\section{Alteridade, signo ideológico e dialogismo}

Entendendo a vida como um acontecimento aberto, e a linguagem a partir do dialogismo, Bakhtin funda, segundo Faraco (2003) e Tezza (2007), uma ética a partir da teoria linguístico-literária. Em $O$ autor e a personagem na atividade estética (Bakhtin, 2011), ao tratar da questão da relação entre o autor e a personagem na literatura, o pensador discute que o lugar externo do autor em relação ao herói, uma posição com excedente de visão, confere ao primeiro a possibilidade de constituir um certo acabamento do segundo. Essa mesma ideia é ampliada por ele para pensar as relações humanas e o papel do outro para a constituição do eu: a necessidade de uma relação alteritária, de um excedente de visão aos outros constituída por uma distância concreta (Bakhtin, 2011, p. 21). Segundo a reflexão do filósofo, enquanto sujeito no mundo da vida, permaneço inacabado, o que permite que eu tenha a possibilidade de agir, caso contrário, estaria preso no mundo do teoricismo, como discutido anteriormente. Nesse constante devir da vida, tenho necessidade estética do olhar do outro, de sua posição com excedente de visão. Posição que constitui acabamentos provisórios de mim, pois só o outro tem o fundo de minha imagem, um excedente de visão de mim que não possuo. Da mesma forma, tenho dele esse excedente que lhe escapa. Assim, nossa individualidade não existiria se o outro não a criasse. Individualidade, enquanto singularidade, portanto, não é composta por uma subjetividade isolada, constituída como submissa ao social ou independente dele. Ao contrário, constitui-se a partir da relação com um outro, uma relação que é ética e estética porque é valorada, pois se dá mediada pela linguagem, situada/orientada nas relações dialógicas entre as vozes sociais.

Em Fragmentos dos anos 1970-1971, (Bakhtin, 2017a) prossegue com sua análise quanto à relação alteritária como base constitutiva do ser: "vivo em um mundo de palavras do outro. E toda a minha vida é uma orientação nesse mundo; é a reação às palavras do outro [...], a começar pela assimilação delas [...] e terminando na assimilação das riquezas da cultura" (Bakhtin, 2017a, p. 38). Nesse universo, tudo o que me diz respeito vem a partir da boca dos outros, de suas palavras, com suas entonações e valores. Dessa forma, "tomo consciência de mim através dos outros: deles eu recebo as palavras, as formas e a tonalidade para a formação da primeira noção de mim mesmo” (Bakhtin, 2017a, p. 30).

Ainda nas palavras de Bakhtin (2011, p. 13), em nossas ações, “avaliamos a nós mesmos do ponto de vista do outros, através do outro procuramos compreender e levar em conta os momentos transgredientes à nossa própria consciência”. Porém, nesse processo não há um desligamento/separação do meu ser-evento, existir que se mantém em constante devir, o que faz com que, para viver, "preciso ser inacabado, aberto para mim" (Bakhtin, 2011 , p. 11). Desse modo, afirma o filósofo, na vida, "ao olharmos para nós mesmos com os olhos do outro, na vida sempre tornamos a voltar para nós mesmos, e o último acontecimento, espécie de resumo, realiza-se em nós nas categorias da nossa própria vida" (Bakhtin, 2011, p. 14). Nesse sentido, o olhar e as palavras do outro nos constituem, mas não nos determinam, pois o ato na vida é sempre singular, responsivo e responsável.

A relação alteritária, a presença e a palavra do outro, a entonação e os valores também se constituem como centrais nas discussões presentes em MFL, no qual Volóchinov (2017) apresenta um dos aspectos centrais da filosofia do Círculo - a teoria do signo ideológico. Nesta obra, discute que o domínio do ideológico coincide com o domínio dos signos. Ideológico, nesse contexto, refere-se a uma dimensão avaliativa e que expressa sempre um posicionamento social valorativo. Assim, não há palavra ou enunciado que não seja ideológi- 
co, que não expresse valor produzido social e historicamente. Nas palavras de Volóchinov (2017, p. 93 - grifos do autor), "O campo ideológico coincide com o campo dos signos. Eles podem ser igualados. Onde há signo há também ideologia. Tudo que é ideológico possui significação sígnica”. Com base nessa compreensão, Volóchinov (2017) discute dois aspectos: primeiro, que a própria consciência humana se constitui a partir de matéria significante (signos), e de que, segundo, os signos são constituídos a partir de relações humanas, nunca provém de uma consciência individual.

Assim, Volóchinov (2017) tece suas críticas ao modo de compreensão vigente da formação da consciência: segundo o idealismo, ela "se torna tudo, e é colocada em algum lugar acima da existência, passando a defini-la" (p. 96); segundo o positivismo, ela "se torna nada: ela é uma soma de reações psicofisiológicas ocasionais" (p. 96). Passam, pois, os autores do Círculo, a sustentar a compreensão de que "a própria consciência pode se realizar e se tornar um fato efetivo apenas encarnada em um material sígnico” (Volóchinov, 2017, p. 95). Nesse processo, "a consciência individual se nutre dos signos, cresce a partir deles, reflete em si a sua lógica e as suas leis” (Volóchinov, 2017, pp. 97-98). A teoria do signo será a base de sustentação para a compreensão de que nossa relação com o mundo, ou a relação de nosso dizer com as coisas, não é direta, se dá sempre de modo oblíquo. As relações que traçamos cotidianamente, portanto, se constituem "enformadas" em signos, ou seja, o mundo só tem sentido quando transformado em signo - ou quando "semioticizado", como analisa Faraco (2003, p. 49). Por conseguinte, a palavra é apontada por Volóchinov (2017, p. 98) como o "fenômeno ideológico par excellence", pois tem toda sua realidade absorvida por sua função de signo - trata-se do "medium mais apurado e sensível da comunicação social” (Volóchinov, 2017, pp. 98-99 - grifos do autor). Assim, é “na” e "pela” palavra que é possível apreender movimentações de (re)construção e de transformação de significações que produzem, como efeito, a composição de cenários das experiências cotidianas de uma sociedade - movimentações e transformações das condições de existência.

Na palavra se realizam os inúmeros fios ideológicos que penetram todas as áreas da comunicação social. É bastante óbvio que a palavra será o indicador mais sensível das mudanças sociais, sendo que isso ocorre lá onde essas mudanças ainda estão se formando, onde elas ainda não se constituíram em sistemas ideológicos organizados. A palavra é o meio em que ocorrem as lentas acumulações quantitativas daquelas mudanças que ainda não tiveram tempo de alcançar uma nova qualidade ideológica nem de gerar uma nova forma ideológica acabada. A palavra é capaz de fixar todas as fases transitórias das mudanças sociais, por mais delicadas e passageiras que elas sejam. (Volóchinov, 2017, p. 106 - grifos do autor)

A constituição da palavra como signo ideológico não se dá, pois, a partir da consciência individual, pois o signo "só pode surgir em território interindividual" (Volóchinov, 2017, p. 96) - marca-se, mais uma vez, a centralidade e a importância da alteridade na filosofia do Círculo. Assim, "as formas do signo são condicionadas, antes de tudo, tanto pela organização social desses indivíduos quanto pelas condições mais próximas da sua interação" (Volóchinov, 2017, p. 109) - novamente destacam-se as condições materiais e históricas, o caráter singular e único. A constituição do sentido, da mesma forma, só estará ligada e arraigada ao terreno interindividual e também terá a situação, local, tempo, relações hierárquicas, atitudes, valorações e entonações dos falantes, aquilo de que se fala, etc., como "parte integral necessária de sua composição semântica" (Volochínov, 2013b, p. 
79). Assim, não é possível arrancar a enunciação do contex to no qual e do qual ela emerge, pois, "por mais que se quebre a cabeça, não se compreenderá o significado dessa enunciação se não se conhecem todas as condições nas quais ela foi pronunciada” (Volochínov, 2013a, p. 171).

A constituição da palavra como signo ideológico resulta de consensos provisórios entre indivíduos organizados socialmente em um processo de interação. Esses consensos não são estáticos ou finais, pois não há fim no processo de produção de sentidos, não há palavra última, como afirma Bakhtin (2017b). Na e pela linguagem é que os grupos humanos produzem sentidos com os quais se relacionam entre si, consigo mesmos e com o mundo. A linguagem, portanto, reflete e refrata os modos como cada grupo humano recobre o mundo com diferentes valores ideológicos. Esses múltiplos sentidos constituídos por grupos são compreendidos, a partir da teoria do signo ideológico, como vozes sociais. As diversas vozes sociais estão sempre em tensão, em um constante jogo de poder, na busca por significações finais e estáticas, a produzir a "monologia" enquanto efeito de sentido no qual uma só voz se faz ouvir. Nesse embate entre as vozes sociais é possível identificar forças centrípetas, que buscam subjugar sentidos, homogeneizá-los, e forças centrífugas (valores outros), que tentam depor uma hegemonia instaurada, denunciando que as significações nunca são encerradas, como analisa Faraco (2003, p. 67).

Com base na compreensão de que todas as esferas da atividade humana estão sempre vinculadas à linguagem (conforme teoria do signo ideológico), esta se dá sob a forma de enunciados, considerados como "unidade real da comunicação discursiva" (Bakhtin, 2016, p. 22). O ato enunciativo, tendo reconhecido seu caráter singular, se dará a partir de "tipos relativamente estáveis de enunciados" (Bakhtin, 2016, p. 12 - grifo do autor), gêneros do discurso. Embora singular, individual e criativo, o enunciado não pode ser considerado uma combinação livre de formas da língua. Essa relativa estabilidade da composição do enunciado é o que permite a comunicação entre indivíduos. Porém, com base na teoria do signo ideológico, fica evidente na leitura da filosofia do Círculo que a linguagem não é apenas meio de comunicação, como as teorias formalistas e estruturalistas a apresentam. A linguagem é um emaranhado de vozes sociais, de valores, no qual o sujeito se posiciona ao enunciar e ao fazê-lo abre possibilidades para contrapalavras, em uma cadeia responsiva. Nesse sentido, "a compreensão da fala viva, do enunciado vivo é de natureza ativamente responsiva" (Bakhtin, 2016, p. 25). A compreensão/interpretação de um enunciado produz, no ouvinte/leitor, mesmo que forçosamente, um posicionamento em relação a esse dito.

Também o locutor é um respondente, já que não é o primeiro a enunciar sobre determinado assunto, de determinada forma, com determinada composição - o falante «não é um Adão, e por isso o próprio objeto de seu discurso se torna inevitavelmente um palco de encontro com opiniões de interlocutores imediatos" (Bakhtin, 2016, p. 61). Esse locutor, enquanto também um respondente, está inserido num mundo de falas anteriores, que suscitaram dele respostas, às quais o seu enunciado está atrelado. De forma responsiva, o enunciado é um elo na cadeia da comunicação verbal, carregado de valorações, já que as palavras levam em si, a serviço de um locutor, um juízo de valor - o que provoca uma compreensão ativa e responsiva. Diálogo, para o Círculo de Bakhtin, refere-se a essa cadeia conectiva, ao diálogo entre vozes sociais que se constitui como uma imensa teia, repleta de atravessamentos; um continuum com base num já dito (no passado - retrospectivamente) e numa compreensão, que sempre é ativa porque posicionada (no futuro - prospectivamente). Nas palavras de Bakhtin: 
Não existe a primeira nem a última palavra, e não há limites para o contexto dialógico (este se estende ao passado sem limites e ao futuro sem limites). Mesmo os sentidos do passado, isto é, nascidos no diálogo dos séculos passados, jamais podem ser estáveis (concluídos, acabados de uma vez por todas): eles sempre hão de mudar (renovando-se) no processo do futuro desenvolvimento do diálogo. Em qualquer momento do desenvolvimento do diálogo existem massas imensas e ilimitadas de sentidos esquecidos, mas em determinados momentos do sucessivo desenvolvimento do diálogo, tais sentidos serão relembrados e reviverão em forma renovada (em um novo contexto). Não existe nada absolutamente morto: cada sentido terá sua festa de renovação. Questão do grande tempo (Bakhtin, 2017b, p. 79 - grifos do autor).

Todo enunciado, portanto, é dialógico, porque inserido nesse grande tempo, é um elo na cadeia enunciativa, "é só um momento, uma gota no rio da comunicação verbal" (Volochínov, 2013a, p. 158). Mas, se todo enunciado é dialógico, como é possível pensar em monologia na filosofia do Círculo? A monologia se produz como efeito de sentido produzido a partir do silenciamento de vozes sociais, na busca por apresentar apenas uma voz homogênea, um enunciado que representa, pretensamente, o objeto numa relação direta, ou seja, para a noção de constituição de uma verdade final e única. Enunciados como esses "têm de monológico apenas sua forma externa. Sua essência, sua construção semântica e estilística são dialógicas” (Volochínov, 2013a, p. 163). Há ainda, em Bakhtin (2017b, p. 69), a monologia como efeito do processo de apropriação da palavra alheia - a consciência monologiza-se no processo de apropriação e reelaboração da palavra. Nesse sentido, a monologia indica também a tomada da palavra como própria, enunciada já "sem aspas", em "discurso direto", como define Volóchinov (2017). Ao enunciar, o sujeito faz uso da palavra como sua; a enuncia como uma voz, abstraindo nesse processo todo o coral e tensões que estão contidas em cada uma das palavras. Monologia resta, assim, como efeito de sentido, produzido em uma determinada situação.

\section{A produção de conhecimentos nas Ciências Humanas e a Psicologia}

Na obra do Círculo de Bakhtin, as propostas epistemológicas e ontológicas andam juntas - a compreensão de formação do sujeito, em sua relação alteritária, num mundo valorado e de constante transformação e diálogo entre vozes sociais, põe a necessidade de reflexão metodológica e ética àquele/a que se dedique a pensar/estudar as relações e processos humanos, dentre os quais estão, obviamente, os estudos da Psicologia. O princípio filosófico do dialogismo nos conduz a refletir sobre uma proposta outra de produção de conhecimentos que, de forma evidente, se contrapõe à das vozes da Modernidade. O dialogismo conduz a refletir sobre três principais aspectos, interligados e inseparáveis: o lugar do/a pesquisador/a e de seu/sua outro/a; e a escrita, ou a redação científica; e o ideal de verdade ao conhecimento produzido.

Sobre o primeiro ponto, o lugar do/a pesquisador/a e de seu/sua outro/a, a filosofia do Círculo rompe com a ideia de individuo, de sujeito autônomo do modernismo-capitalismo sustentando a compreensão de sujeito sempre em relação, formado a partir do universo semiótico-valorativo e que tem a necessidade ético-estética do outro como possibilidade de acabamento. Isso implica ao/à pesquisador/a assumir um lugar que também é outro, que 
não é o da transparência e o da neutralidade pressupostos ou que se tentam construir com instrumentos precisos e previamente delimitados. Trata-se de um lugar de implicação, de produção das relações, de sentidos, de diálogos. O lugar do/a pesquisador/a será, pois, sempre o de um sujeito inserido/a nas e constituído pelas tramas dialógicas que procura analisar, alguém posicionado, prenhe de valores e que responde a e por eles.

Essa posição do/a pesquisador/a implica-o/a como participante, sujeito presente com seu ser-evento em processo com outros seres-evento. Assim, o participar do/a pesquisador/a não significa apenas aceitar que suas ações produzem reflexos sobre o agir do outro, mas de adotar uma posição de negação completa da possibilidade de transparência da linguagem e do assumir uma relação eu-outro em sua integralidade, no mundo da vida. Sua ação será sempre valorada, e nunca neutra, pois sempre se pautará em valores enunciados por vozes sociais que o/a constituem como sujeito no mundo - não há, como diz Bakhtin (2010), álibi no existir, a neutralidade não é possível - isso acarreta a uma inevitável assumpção de um caráter responsivo e ético sobre sua ação de pesquisa (Jobim e Souza \& Carvalho, 2016). Toda pesquisa terá, pois, um caráter interventivo, pois algo será produzido nessa relação, novos sentidos, novas tensões (Brito \& Zanella, 2017; Freitas, 2010; Maraschin, 2004; Spink, 1999). O dialogismo afirmado pelo Círculo implica, pois, repensar a configuração da relação entre pesquisador/a e seu/sua outro/a - uma relação alteritária de mútua constituição (Amorim, 2002, 2004; Jobim e Souza \& Albuquerque, 2012). Metodologicamente, o/a pesquisador/a não é um/a perguntador/a, mas um sujeito em interação com outros/as, ele/a é participante da produção de sentidos que serão analisados. Analisar esses sentidos, por conseguinte, implica pensá-los como resultado da interação situada no tempo e no espaço, entremeada por relações de poder, imaginários etc., e não como ação do sujeito ou grupo estudado. A pesquisa, portanto, não se constitui "sobre o outro" e seu universo semiótico/ideológico, mas sim como pesquisa que se dá "com o/a outro/a”, uma produção da qual o/a pesquisador/a faz parte e ativamente participa. As imagens/lugares de pesquisador/a e pesquisados/as/participantes (como o/a participante vê/compreende o/a pesquisador/a e vice-versa, a relação hierárquica que se institui, as tensões em jogo), são constitutivas dos sentidos produzidos nas situações de interação, os quais precisam ser pensados/analisados à luz da compreensão dessa relação.

Nesse sentido, o/a pesquisador/a passa a ser um/a sujeito/a em interação, e não mais alguém que contempla um objeto e se pronuncia sobre ele. Obviamente, como ressalta Bakhtin (2010, 2017b), o humano pode ser estudado a título de coisa, porém, não pode se manter como tal, pois ocupará sempre um lugar nas tramas dialógicas, estará sempre em interação, inserido na vida em constante devir, não cessando de agir, e seu ato não pode ser descrito ou previsto em sua totalidade (se assim o fosse, o mundo teórico coincidiria com o da vida concreta). Mantendo esse lugar de sujeito ao/à outro/a, eu, pesquisador/a, só poderei me pronunciar sobre ele/a, produzindo, necessariamente, um acabamento de sua imagem a partir de meu posicionamento externo, de meu olhar exotópico concreto, assim como ele/a o faz para comigo. Esse acabamento, porém, não pode ser compreendido como a totalidade desse outro, pois compõe já uma abstração de sua existência, sua singularidade, que só pode ser vivenciada e experienciada por ele/a (Bakhtin, 2010). O acabamento é sempre o possível naquele contex to e condições, valorado e situado no tempo e no espaço.

O saber que se produz com o/a outro/a será, pois, voltado à cena/arena enunciativa das relações, aos sentidos que são postos em tensão e produzidos nessas situações (atualizados, refutados, tensionados, recriados etc.). Os sentidos que emergem nas situações de 
pesquisa já são também objetos habitados, o/a pesquisador/a não é um Adão a desvela-los pela primeira vez, em menção a metáfora bakhtiniana. Assim, manter o caráter dialógico e a condição de sujeito, não de "coisa muda" do outro, implica resgatar e fazer falar as diversas vozes, principalmente as que são subsumidas, nos processos de interlocução; de que modo esses complexos semiótico-valorativos participam/constituem as cenas enunciativas, os lugares de cada um/a nessa cena e nos sentidos que são (re)criados e (trans) formados.

Com a discussão apresentada já adiantamos algumas questões referentes ao segundo ponto, a escrita da/na pesquisa. Ao debruçar-se sobre o produzido na situação de pesquisa, o/a pesquisador/a precisa assumir a impossibilidade de restituição do sentido tal qual na situação concreta, vivida, pois o texto da pesquisa constitui-se "com" e "como" um outro contexto (Volochínov, 2013a). Um outro momento do constante devir do/a próprio/a pesquisador/a que, no fluxo da vida, não pode aprisionar sentidos que estão em constante tensão, negociação e produção. A narrativa emerge, assim, como possibilidade (com seus limites) de constituição da cena enunciativa, não no sentido de produção de análise que traduza a totalidade dos sentidos, mas como aproximação do ato, do mundo da vida, ao universo abstrato da escrita, como leitura de um enunciado e das vozes que falam nele e por ele a partir, também, de seu caráter situado no tempo e espaço. Do mesmo modo, o debruçar-se sobre os materiais produzidos implica a reflexão e posicionamento ético e político (Amorim, 2004; Jobim e Souza \& Albuquerque, 2012) - e aí, novamente, como em toda a vida, não há álibi -, sobre o que se faz com esse/a outro/a em meu texto: se minha voz produz, como efeito, o apagamento de sua singularidade, um simulacro, encerrando sua existência numa ideia de totalidade que o/a aprisiona, ou construo acabamento estético que possa refletir seu ser-evento em processo; se acabo ou não por produzir o aprisionamento de meu/minha outro/a num mundo no qual não seja possível agir; se não o transformo em "coisa muda"; se o conhecimento que estou tecendo produz ou não como efeito a monologia (Bakhtin, 2017 b, p. 66).

Do mesmo modo, quanto ao último ponto elencado (o ideal de verdade sobre o conhecimento produzido), no contexto dialógico não há primeira nem última palavra, as vozes sociais estão em constante diálogo e tensão, os sentidos estão em constante transformação e produção; por conseguinte, os objetos já são habitados por diversas vozes e põem como possibilidade e limite que todo saber produzido sobre eles é um saber situado no tempo e no espaço, realizado por determinadas pessoas, em determinadas condições. Todo saber, portanto, é datado e não final, assim como a monologia emerge apenas como efeito de sentido de uma voz que se pretenda final ou concluidora de sentidos.

Se, a princípio, possa parecer que estamos sendo conduzidos/as a um relativismo absoluto, o que se propõe é o contrário. Trata-se de um retorno às condições nas quais o saber é produzido, de reflexão sobre processos, valores e vozes envolvidos, e de assumir, inevitavelmente, um posicionamento ético-estético e político; trata-se de uma espécie de reconhecimento de que a ação humana não pode ser aprisionada no mundo teórico, não pode ser predita em sua totalidade, pois na e pela ação os sujeitos se constroem, se transformam, se modificam; trata-se da centralidade no reconhecimento de que a ação humana é sempre situada, respondendo a enunciados anteriores e abrindo-se a novos enunciados; de que a ação é sempre singular e irrepetível, contrapondo-se, pois, aos ideais de regularidade e repetibilidade da Modernidade. O reconhecimento de um saber que não seja final (istina), mas sim que é situado, do momento (pravda), não significa, pois, cair no relativismo abso- 
luto, mas sim na possibilidade de não fechamento do/a outro/a à condição de coisa muda. Todo conhecimento produzido insere-se, portanto, na teia dialógica, como mais um enunciado que não pode finalizar o diálogo entre as vozes sociais. Assim, tem-se uma ruptura quanto ao status de verdade da ciência, apresentando o conhecimento como mais um elo de uma cadeia sem fim. Um acabamento momentâneo que não pode abarcar a totalidade o conhecimento sempre como uma abstração, que compõe o mundo da cultura e que não pode abarcar a totalidade da vida em devir.

Ainda, ao se contraporem aos ideais da Modernidade, os pensadores do Círculo não buscam constituir uma única proposta à produção de conhecimento (ciência). Ao contrário, denunciam a impossibilidade de uma unicidade quanto a ele, principalmente no que se refere às ciências humanas, ou ao estudo do humano. Não constituem, portanto, proposta de uma outra forma de obtenção da verdade final, que se pretenda constituidora do conhecimento verdadeiro - fazer isso seria cair novamente na proposta moderna. O rigor, talvez possamos concluir, que na Modernidade estava em seguir regras e passos que pudessem garantir a neutralidade ou não interferência do/a pesquisador/a, na Filosofia do Círculo reside na problematização constante de seu lugar na trama do pesquisar, no posicionamento ético, estético e político daquele/a que se aventura a estudar e pensar o humano e seus processos.

\section{Algumas palavras mais}

O Círculo de Bakhtin era composto por um grupo de pensadores de diversas áreas; sua obra, inserida nas teias dialógicas, responde a diversas vozes sociais, não exclusivamente as dos pensadores da Modernidade. Nos textos escritos pelo Círculo, é possível, pois, ver/ouvir uma grande quantidade de vozes outras, as quais não exploramos neste texto. O que fizemos foi buscar evidenciar posicionamentos refratários do Círculo aos modernistas, assim como delinear alguns pontos basilares de sua proposta para pensar o conhecimento, sua produção e seus limites e de como isso pode nos auxiliar no processo de produção de conhecimentos em Psicologia. Da mesma forma, a incursão que realizamos, e aqui apresentamos, não tem por intenção esgotar, ou apresentar uma totalidade em relação ao posicionamento do Círculo frente aos ideais modernos. Trata-se, como afirmamos de início, de um ensaio, produzido no diálogo com alguns textos que compõem um complexo filosófico coeso, produzido pelos pensadores que o integram. Nesse sentido, o que apresentamos expressa um tanto dessa coesão, de princípios filosóficos que se sustentam e que estão presentes nas obras todas.

Para a produção do conhecimento no campo das humanidades, podemos depreender do diálogo que aqui apresentamos que, na ótica do Círculo, o conhecimento: nunca será final (istina), mas sempre situado, datado, localizado e entoado por alguém (pravda); o caráter singular é que ocupa lugar de destaque, e não as regularidades e universalidades; é dialógico, pois a alteridade constitui-se como fundadora do eu - não é possível pensar o sujeito a partir de uma ótica individualista, tomado em separado do outro, e por conseguinte não é possível pensar a pesquisa desconsiderando os muitos outros participantes do diálogo e do processo de produção de sentidos do qual o/a pesquisador/a se apresenta como partícipe. A produção do texto de pesquisa requer, nesse sentido, um determinado acabamento estético, dado pelo/a pesquisador/a a partir de seu posicionamento ético-es- 
tético nas teias dialógicas entre vozes sociais. A esse acabamento, à escrita final do texto, deverá o/a pesquisador/a responder, sem álibi.

Por fim, cabe destacar, que o modo de compreender a possibilidade de produção de conhecimentos em ciências humanas, proposta pelo Círculo, põe todo conhecimento como em constante construção, no qual as produções são enunciados situados no tempo e no espaço, elos inseridos na cadeia de enunciados sem fim. Conhecimento, portanto (dentre os quais está a Psicologia) que precisa ser pensado no "grande tempo", como diz Bakhtin (2017b, p. 79)), considerando as condições de sua própria produção, os efeitos que produz e as tensões que o configuram.

\section{Notas}

1 Neste trabalho, adotamos o termo "Círculo de Bakhtin", já difundido na literatura. Com ela, representa-se um grupo de intelectuais (dentre os quais estão Mikhail Bakhtin, Valentin Volóchinov e Pavel Medvedev) que produziu um conjunto denso e coeso de obras muito próximas filosoficamente.

2 Mantivemos a referência bibliográfica desta obra (citada mais adiante) conforme sua publicação no Brasil, vinculada à Mikhaill Bakhtin. Porém, reconhecemos Valentín Nikoláievitch Volóchinov como seu autor, pois esse texto consta como componente de relatório de atividades apresentado ao "Instituto da História Comparada das Literaturas e das Línguas do Ocidente e do Oriente" (ILIAZV), lugar onde o pensador atuou entre 1925 e 1932, conforme Grillo, Sheila Vieira de Camargo. (2017). Marxismo, psicanálise e método sociológico: o diálogo de Volóchinov, marxistas soviéticos e europeus com Freud. Bakhtiniana: Revista de Estudos do Discurso, 12(3), 54-75. https://dx.doi.org/10.1590/2176457332107. Ademais a questão da autoria do texto, ele compõe, conforme nota anterior, uma totalidade filosófica compreendida como do Círculo de Bakhtin.

\section{Referências}

Amorim, M. (2002). Vozes e silêncio no texto de pesquisa em Ciências Humanas. Cadernos de Pesquisa, 116, 7-19. http://doi.org/10.1590/So100-1574200200020000 1

Amorim, M. (2004). O pesquisador e seu outro: Bakhtin nas Ciências Humanas. São Paulo: Musa Editora.

Bacon, F. (2003). Novo Organum - ou Verdadeiras indicações acerca da interpretação da natureza. Pará de Minas, MG: Virtualbooks. Recuperado de http://www2.ufpa.br/ensinofts/cts/francis_bacon_novum_organum.pdf

Bakhtin, M. (2004). O Freudismo: um esboço crítico. São Paulo: Perspectiva.

Bakhtin, M. (2010). Para uma filosofia do ato responsável. São Carlos, SP: Pedro \& João Editores. Bakhtin, M. (2011). O autor e a personagem na atividade estética. In Estética da Criação Verbal (6 ed., pp. 3-194). São Paulo: Martins Fontes.

Bakhtin, M. (2016). Os gêneros do discurso. São Paulo: Editora 34.

Bakhtin, M. (2017a). Fragmentos dos anos 1970-1971. In Notas sobre literatura, cultura e ciências humanas (1 ${ }^{\mathrm{a}}$ ed., pp. 21-56). São Paulo: Editora 34. 
Bakhtin, M. (2017b). Por uma metodologia das ciências humanas. In Notas sobre literatura, cultura e ciências humanas (pp. 57-79). São Paulo: Editora 34.

Benjamin, W. (2015). Baudelaire e a modernidade. Belo Horizonte: Autêntica.

Brito, R. D. V.A. \& Zanella, A. V. (2017). Formação ética, estética e política em oficinas com jovens: tensões, transgressões e inquietações na pesquisa-intervenção. Bakhtiniana: Revista de Estudos Do Discurso, 12(1), 42-64. http://doi.org/http://dx.doi.org/10.1590/2 176-457326093 Descartes, R. (1989). Regras para a direção do espírito. Lisboa: Edições 70.

Descartes, R. (1996). Discurso do Método ( $3^{\mathrm{a}}$ ed.). São Paulo: Martins Fontes.

Elias, N. (1998). Sobre o Tempo. Rio de Janeiro: Jorge Zahar.

Faraco, C. A. (2003). Linguagem e Diálogo: as idéias linguísticas do círculo de Bakhtin. Curitiba: Criar Edições.

Figueiredo, L. C. (2000). Matrizes do pensamento psicológico. Petrópolis, RJ: Vozes.

Freitas, M. T. A. (2010). Discutindo sentidos da palavra intervenção na pesquisa de abordagem historico-cultural. In M. T. A. Freitas \& B. S. Ramos (Eds.), Fazer pesquisa na abordagem histórico-cultura: metodologias em construção (pp. 13-24). Juiz de Fora, MG: Ed. UFJF.

Ginzburg, C. (1989). Mitos, emblemas, sinais: morfologia e história. São Paulo: Companhia das Letras.

Jobim e Souza, S. \& Albuquerque, E. D. P. (2012). A pesquisa em ciências humanas : uma leitura bakhtiniana / Research in human sciences : a Bakhtinian reader. Bakhtiniana: Revista de Estudos Do Discurso, 7(2), 109-122. Recuperado de http://revistas.pucsp.br/index.php/ bakhtiniana/article/view/8124/9331

Jobim e Souza, S. \& Carvalho, C. S. (2016). Ética e pesquisa: o compromisso com o discurso do outro. Polis e Psique, 6(1), 98-112.

Lefebvre, H. (1991). A vida cotidiana no mundo moderno. São Paulo: Ática.

Lefebvre, H. (2013). La Producción del espacio. Madrid: Capitán Swing Libros.

Maraschin, C. (2004). Pesquisar e intervir. Psicologia \& Sociedade, 16(1), 98-107.

Ponzio, A. (2010). A concepção bakhtiniana do ato como dar um passo. In M. Bakhtin (Ed.), Para uma filosofia do ato responsável (pp. 9-38). São Carlos, SP: Pedro \& João Editores.

Santos, B. S. (2008). Um discurso sobre as ciências. São Paulo: Cortez.

Santos, M. (2014). A natureza do espaço: Técnica e Tempo, Razão e Emoção (8 ${ }^{\mathrm{a}}$ ed.). São Paulo: Edusp.

Saussure, F. (2006). Curso de linguistica geral. São Paulo: Cultrix.

Sobral, A. U. (2005). Ato/atividade e evento. In B. Brait (Ed.), Bakhtin: conceitos-chave (pp. 1136). São Paulo: Contexto.

Spink, M. J. P. (1999). Práticas discursivas e produção de sentidos no cotidiano: aproximações teóricas e metodológicas. São Paulo: Cortez.

Tezza, C. (2007). Sobre o autor e o herói. In C. A. Faraco, C. Tezza, \& G. Castro (Eds.), Diálogos com Bakhtin (pp. 231-256). Curitiba: UFPR.

Volochínov, V. N. (2013a). A construção da enunciação. In A construção da enunciação e outros ensaios (pp. 157-188). São Carlos, SP: Pedro \& João Editores.

Volochínov, V. N. (2013b). Palavra na vida de a palavra na poesia. In A construção da enunciação e outros ensaios (pp. 71-100). São Carlos, SP: Pedro \& João Editores.

Volóchinov, V. N. (2017). Marxismo e filosofia da linaguagem: problemas fundamentais do método sociológico na ciência da cinguagem. São Paulo: Editora 34. 


\section{JARDEL PELISSARI MACHADO \\ https://orcid.org/0000-0001-9840-8992}

Psicólogo da Universidade Federal do Paraná (UFPR) e doutorando no Programa de Pós-graduação em Psicologia da Universidade Federal de Santa Catarina (UFSC).

Endereço institucional: Rua Ubaldino do Amaral, 32 1, 1. ${ }^{\circ}$ andar. CEP 80045100 Curitiba-PR.

E-mail: machado.jardel@,ufpr.br

\section{ANIDREA VIEIRA ZANELLA \\ https://orcid.org/0000-0001-8949-0605}

Professora titular da Universidade Federal de Santa Catarina, orientadora de mestrado e doutorado vinculada ao Programa de Pós-graduação em Psicologia da UFSC. Realizou em 2016 estágio sênior na New School for Social Research com bolsa CAPES.

E-mail: a.zanella@ufsc.br

$\begin{array}{ll} & \text { Submissão: } 10 / 07 / 2016 \\ \text { Hevisão: } 02 / 11 / 2019 & \\ & \text { Aceite: 01/03/2019 } \\ \text { Bolsa de Produtividade em Pesquisa CNPq (An- } & \text { drea Vieira Zanella) } \\ \text { Financiamento } & \text { Concepção: JPM; AVZ } \\ & \text { Coleta de dados: JPM; AVZ } \\ & \text { Análise de dados: JPM; AVZ } \\ & \text { Elaboração do manuscrito: JPM; AVZ } \\ \text { Crítica de conteúdo intelectual } & \text { importante: JPM; AVZ } \\ \text { Contribuição dos autores } & \text { Aprovação final do manuscrito: JPM; AVZ } \\ & \text { Não se aplica }\end{array}$

